\title{
The Hippocampus and Cingulate Cortex Differentially Mediate the Effects of Nicotine on Learning Versus on Ethanol-Induced Learning Deficits Through Different Effects at Nicotinic Receptors
}

\author{
Danielle Gulick' and Thomas J Gould*' \\ 'Department of Psychology, Neuroscience Program, Center for Substance Abuse Research, Temple University, Philadelphia, PA, USA
}

\begin{abstract}
The current study examined the effects of nicotine infusion into the dorsal hippocampus or anterior cingulate on fear conditioning and on ethanol-induced deficits in fear conditioning, and whether these effects involved receptor activation or inactivation. Conditioning consisted of two white noise $(30 \mathrm{~s}, 85 \mathrm{~dB})$-foot-shock $(2 \mathrm{~s}, 0.57 \mathrm{~mA})$ pairings. Saline or ethanol was administered to C57BL/6 mice 15 min before training and saline or nicotine was administered 5 min before training or before training and testing. The ability of the highaffinity nicotinic acetylcholinergic receptor ( $\mathrm{nAChR}$ ) antagonist dihydro- $\beta$-erythroidine (DH $\beta \mathrm{E})$ to modulate the effects of ethanol and nicotine was also tested; saline or DH $\beta$ E was administered 25 (injection) or 15 (infusion) minutes before training or before training and testing. Infusion of nicotine into the hippocampus enhanced contextual fear conditioning but had no effect on ethanol-induced learning deficits. Infusion of nicotine into the anterior cingulate ameliorated ethanol-induced deficits in contextual and cued fear conditioning but had no effect on learning in ethanol-naive mice. $\mathrm{DH} \beta \mathrm{E}$ blocked the effects of nicotine on ethanol-induced deficits; interestingly, $\mathrm{DH} \beta \mathrm{E}$ alone and co-administration of subthreshold doses of $\mathrm{DH} \beta \mathrm{E}$ and nicotine also ameliorated ethanol-induced deficits but failed to enhance learning. Finally, $\mathrm{DH} \beta \mathrm{E}$ failed to ameliorate ethanol-induced deficits in $\beta 2 \mathrm{nAChR}$ subunit knockout mice. These results suggest that nicotine acts in the hippocampus to enhance contextual learning, but acts in the cingulate to ameliorate ethanol-induced learning deficits through inactivation of high-affinity $\beta 2$ subunit-containing nAChRs.

Neuropsychopharmacology (2009) 34, 2167-2 179; doi:I0.1038/npp.2009.45; published online 29 April 2009
\end{abstract}

Keywords: alcohol; addiction; learning and memory; hippocampus; anterior cingulate

\section{INTRODUCTION}

Despite the well-known consequences of alcohol and nicotine consumption, abuse and co-abuse of these drugs remain a major societal issue. A positive correlation exists between high-risk, heavy use of each drug (Dawson, 2000; John et al, 2003; Larsson and Engel, 2004). There is also a correlation between dependence on alcohol and dependence on nicotine; the National Institute of Health (2007) reports that nicotine-addicted smokers are four times more likely than non-smokers to also be addicted to alcohol, and that alcoholics are three times more likely than the rest of the population to smoke cigarettes.

Although alcohol and nicotine have anxiolytic (Blanchard et al, 1993; Picciotto et al, 2002) and rewarding (White,

\footnotetext{
*Correspondence: Dr TJ Gould, Department of Psychology, Temple University, Weiss Hall, Center for Substance Abuse Research, Philadelphia, PA, 19122, USA, Tel: 215204 7495, Fax: 215204 5539, E-mail: tgould@temple.edu

Received 17 December 2008; revised 13 March 2009; accepted 6 April 2009
}

1996) effects, the co-abuse of these drugs may also result from the interaction of these drugs on cognitive function. For instance, ethanol disrupts contextual and cued fear conditioning (Escher and Mittleman, 2004; Gould, 2003; Gulick and Gould, 2007), whereas nicotine enhances contextual but not cued fear conditioning (Gould and Higgins, 2003a; Gould and Wehner, 1999) and ameliorates ethanol-induced deficits in both contextual and cued fear conditioning (Gould and Lommock, 2003b; Gulick and Gould, 2008). However, it is unclear whether the same mechanism involved in the enhancement of contextual fear conditioning by nicotine mediates nicotine amelioration of ethanol-induced deficits in fear conditioning.

Although nicotine infusion into the dorsal hippocampus enhances contextual fear conditioning (Davis et al, 2007), it is unknown if nicotine acts in this area to ameliorate ethanol-induced learning deficits. Nicotine modulates ethanol-induced deficits in both cued and contextual fear conditioning. Cued fear conditioning, however, is hippocampus-independent (Logue et al, 1997; Phillips and LeDoux, 1992); thus, nicotine may act in another brain 
area to ameliorate ethanol-induced deficits in contextual and cued fear conditioning. The anterior cingulate is critically involved in attentional processes (Allman et al, 2001), and mnemonic processes (Chiba et al, 1997; Faw, 2003; Malin et al, 2007; Malin and McGaugh, 2006; Tang et al, 2005). With roles in both attention and learning, the anterior cingulate represents an area where nicotine may act to alter ethanol-induced deficits in fear conditioning.

Just as the brain areas involved in the interactive effects of ethanol and nicotine on learning are unknown, so are the underlying receptor-level processes. Neuronal nicotinic acetylcholinergic receptors (nAChRs) are a broad family of pentameric ion channels comprised of either $\alpha(\alpha 2-10)$ or $\alpha$ and $\beta(\beta 2-4)$ subunits (Decker et al, 1995). $\beta 2$-containing nAChRs are involved in both the nicotine enhancement of learning (Davis et al, 2007) and the interactive effects of nicotine and ethanol on learning (Wehner et al, 2004). Furthermore, $\alpha 4 \beta 2 *(*$ denotes potential unknown additional subunits) nAChRs are found in the dorsal hippocampus and anterior cingulate cortex (Alkondon and Albuquerque, 1993; Pichika et al, 2006). However, nicotine can both activate and desensitize nAChRs (for review, Picciotto et al, 2008); thus, nAChR activation and inactivation may differentially modulate the effects of nicotine on learning and on ethanol-induced deficits in learning.

In the current study, we compared the effects of nicotine infusion into the dorsal hippocampus and anterior cingulate on learning and on ethanol-induced deficits in learning. We also compared the effects of cingulate infusion of nicotine versus dihydro- $\beta$-erythroidine $(\mathrm{DH} \beta \mathrm{E}$, a high-affinity $\mathrm{nAChR}$ antagonist) on ethanol-induced learning deficits to determine whether receptor activation or inactivation can ameliorate these deficits. Because $\mathrm{DH} \beta \mathrm{E}$ antagonizes multiple high-affinity nAChRs (Harvey et al, 1996; Williams and Robinson, 1984), $\beta 2 \mathrm{nAChR}$ subunit knockout (KO) mice were used to test if the effects of $\mathrm{DH} \beta \mathrm{E}$ on ethanol-induced fear conditioning deficits involve $\beta 2$-containing nAChRs.

\section{MATERIALS AND METHODS}

\section{Subjects}

Male C57BL/6J mice (Jackson Laboratory, Bar Harbor, ME) were tested at 8-12 weeks of age (20-30 g). Heterozygous $\beta 2$ $\mathrm{nAChR}$ subunit knockout (KO) mice (original breeding pairs were backcrossed to C57BL/6 mice for at least seven generations and provided by Dr Arthur Beaudet, Baylor College of Medicine) were bred to obtain male and female $\beta 2 \mathrm{nAChR}$ subunit KO mice (ages 8-12 weeks), and wildtype littermates (WT; 8-12 weeks of age); genotype was verified by PCR. Numerous studies have used the $\beta 2 \mathrm{KO}$ mice backcrossed onto a C57BL/6 background to investigate the effects of nicotine on behavior and brain function (Portugal et al, 2008; Raybuck and Gould, 2009; Salas et al, 2004; Wehner et al, 2004). Mice were housed in groups of four per cage before surgery and individually housed after surgery. Mice had ad libitum access to food and water. A 12-hr light-dark cycle (lights on at 0700 hours) was maintained, with all testing done between 0900 and 1700 hours. Procedures were approved by the Temple University Institutional Animal Care and Use Committee.

\section{Apparatus}

Training and context testing took place in identical conditioning chambers housed in sound-attenuating boxes (MED Associates, St Albans, VT). Each $17.78 \times 19.05 \times$ $38.10 \mathrm{~cm}$ chamber consisted of Plexiglas panels in the front, back, and ceiling and two stainless-steel walls on the sides. The metal grid floor of each chamber, through which the foot-shock unconditioned stimulus (US; $0.57 \mathrm{~mA}$ for $2 \mathrm{~s}$ ) was delivered, was connected to a shock generator and scrambler. Speakers that delivered a white noise conditioned stimulus (CS; $85 \mathrm{~dB}$ for $30 \mathrm{~s}$ ) were mounted on the right wall of each chamber. Background noise $(69 \mathrm{~dB})$ and air exchange were provided by ventilation fans mounted on the right wall of each sound-attenuating box. A computer running MED Associates software controlled stimuli presentation. Chambers were cleaned with $70 \%$ ethanol before each session.

Testing for freezing to the CS occurred in a separate room in altered context chambers housed in sound-attenuating boxes. Speakers that delivered the white noise CS were mounted on the left wall of each chamber. The $20.32 \times$ $22.86 \times 17.78 \mathrm{~cm}$ chambers were constructed of four Plexiglas walls, a Plexiglas ceiling, and an opaque white plastic floor. In addition to the differences in location, visual cues (eg, the inside of the sound-attenuating boxes in the training context were white versus black in the altered context room), chamber dimensions, floor construction, and a vanilla extract olfactory cue (no such cue was present at training) further distinguished the altered context chambers from the original training chambers.

\section{Fear Conditioning}

At training, baseline freezing was recorded for the first $120 \mathrm{~s}$ (based on Gould and Higgins, 2003a). At 120 and 270 s, the CS sounded for $30 \mathrm{~s}$; the US occurred during the last $2 \mathrm{~s}$ of the CS; immediate freezing was measured during the intertrial interval. The mice remained in the chamber for $30 \mathrm{~s}$ after the second CS-US presentation. Twenty-four hours later, freezing to the context was assessed for $5 \mathrm{~min}$ and $1 \mathrm{~h}$ later, generalized freezing to the altered context test was measured for $3 \mathrm{~min}$ (pre-CS test) followed by a $3 \mathrm{~min}$ test of freezing to the CS (CS test). Freezing, defined as the absence of visible movement with the exception of respiration, was assessed at $10 \mathrm{~s}$ intervals for $1 \mathrm{~s}$.

\section{Surgery}

Mice were anesthetized using isoflurane gas (5\% induction, $2 \%$ maintenance) and placed in a stereotaxic apparatus from David Kopf Instruments (Tujunga, CA). Bilateral stainless-steel guide cannulae (C232G, 22 gauge; Plastics One, Roanoke, VA) were stereotaxically inserted and fixed to the skull with dental cement. Dummy cannulae (C232DC; Plastics One) were inserted into the guide cannulae to prevent clogging. Coordinates determined from bregma using the mouse brain atlas (Paxinos and Franklin, 2001) were as follows: Hippocampus: $-1.7 \mathrm{~mm}$ posterior; $\pm 1.5 \mathrm{~mm}$ mediolateral; $-2.3 \mathrm{~mm}$ ventral; Cingulate: $+2.0 \mathrm{~mm}$ anterior; $\pm 1.5 \mathrm{~mm}$ mediolateral $( \pm 2.5 \mathrm{~mm}$ mediolateral for lateral controls); $-2.3 \mathrm{~mm}$ ventral $(-4.0 \mathrm{~mm}$ ventral for 
below controls); it should be noted that in rats, functional differences in rostral (2.6 AP rats) and caudal (0.2 AP rats) anterior cingulate cortex (Johansen et al, 2001; Malin et al, 2007) exist. The mouse cingulate cortex extends from 2.34 $\mathrm{AP}$ to $-0.22 \mathrm{AP}$, and then continues to -0.82 as the cingulate/retrosplenial complex. All of our cingulate infusions were restricted to a rostral range of 2.34 to 1.70 AP. Ketoprofen $(2.0 \mathrm{mg} / \mathrm{kg})$ was administered subcutaneously for post-operative pain. Animals were allowed at least 5 days to recover before behavioral procedures began.

\section{Drugs and Infusion}

Nicotine hydrogen tartrate salt (Sigma St. Louis, MO; 0.045 or $0.09 \mathrm{mg} / \mathrm{kg}$ intraperitoneal (i.p.) injection or $0.35 \mu \mathrm{g} /$ $0.50 \mu \mathrm{l} /$ side infusion, reported as freebase weight, based on Davis et al (2007) and Davis and Gould (2006)) and $\mathrm{DH} \beta \mathrm{E}$ (Sigma St. Louis, MO; 3.0 or $6.0 \mathrm{mg} / \mathrm{kg}$ subcutaneous (s.c) injection or $18.0 \mu \mathrm{g} / 0.50 \mu \mathrm{l} /$ side infusion based on Davis et al (2007) and Davis and Gould (2006)) were dissolved in physiological saline; we were unable to test the effects of higher systemic doses of $\mathrm{DH} \beta \mathrm{E}$ as doses of $8.0 \mathrm{mg} / \mathrm{kg}$ or higher induced motor depression. Injection volume for nicotine and $\mathrm{DH} \beta \mathrm{E}$ was $0.01 \mathrm{ml} / \mathrm{g}$ body weight, and for ethanol (Fisher Scientific Pittsburgh, PA; $1.0 \mathrm{~g} / \mathrm{kg}$ i.p. based on Gould, 2003) it was $20 \% \mathrm{vol} / \mathrm{vol}$ in saline. Controls received physiological saline. $\mathrm{DH} \beta \mathrm{E}$ was infused (15 min) or injected $(25 \mathrm{~min})$ before training or before training and testing, ethanol was injected $15 \mathrm{~min}$ before training, and nicotine was infused or injected $5 \mathrm{~min}$ before training or before training and testing. Injection and infusion times were based on previous research (Davis and Gould, 2006; Davis et al, 2007; Gulick and Gould, 2008).

For direct infusions, mice were gently restrained and dummy cannulae were removed and replaced with 22-G infusion cannulae. Drugs were bilaterally infused at a rate of $0.50 \mu \mathrm{l} / \mathrm{min}$. Infusion cannulae were attached to polyethylene tubing (PE50; Plastics One), which was attached to a $10 \mu \mathrm{l}$ Hamilton (Reno, NV) syringe. Drug administration was controlled by a micro-infusion pump (KDS 100; KD Scientific, New Hope, PA). Injection cannulae were left in place for 1 min after infusion to allow drug diffusion away from the cannula tip.

\section{Histology}

Brains were placed in a $10 \%$ formalin solution (Fisher Scientific, Pittsburgh, PA) for at least $24 \mathrm{~h}$ before $60 \mu \mathrm{m}$ thick coronal sections were sliced at $-18^{\circ} \mathrm{C}$. The sections were stained with cresyl violet and cannula placements were determined using a light microscope. Data from animals with incorrect placements were excluded from statistical analysis $(<10 \%)$.

\section{Experimental Design}

We first tested the effects of nicotine infusion into the dorsal hippocampus or anterior cingulate at both training and testing on systemic ethanol-induced fear conditioning deficits. A second experiment examined whether nicotine administration at training only would be sufficient to ameliorate ethanol-induced cognitive deficits; the effects of systemic nicotine administration were tested first, followed by a test of the effects of direct infusion of nicotine into the cingulate cortex. To ensure that the effect of nicotine was specific to the anterior cingulate, we infused nicotine below and lateral to the anterior cingulate infusion site.

To determine if $\mathrm{DH} \beta \mathrm{E}$ alters nicotine amelioration of ethanol-induced learning deficits, we systemically administered ethanol, nicotine, and $\mathrm{DH} \beta \mathrm{E}$ before training. A followup experiment determined whether infusion of $\mathrm{DH} \beta \mathrm{E}$ into the anterior cingulate cortex would alter the effects of systemic nicotine and ethanol on fear conditioning. Finally, we examined whether the effects of $\mathrm{DH} \beta \mathrm{E}$ on ethanolinduced learning deficits involve $\beta 2$-containing $\mathrm{nAChRs}$ by systemically administering the drugs to $\beta 2 \mathrm{KO}$ and WT mice.

\section{Shock Sensitivity}

We next determined whether the interactive effects of ethanol and nicotine on fear conditioning were mediated by changes in shock sensitivity. Animals were systemically administered either saline, $1.0 \mathrm{~g} / \mathrm{kg}$ ethanol (10 min before testing), or $0.09 \mathrm{mg} / \mathrm{kg}$ nicotine (immediately before testing), and then exposed to a range of $2 \mathrm{~s}$ foot shocks $(0.10-$ $0.60 \mathrm{~mA}$ ) over a $15 \mathrm{~m}$ in testing period. There were three presentations at each shock intensity, with a $20 \mathrm{~s}$ interstimulus interval and a $90 \mathrm{~s}$ inter-trial interval. Each animal was administered all three drug treatments, one on each of three consecutive days, and testing sessions occurred $24 \mathrm{~h}$ apart with counterbalancing of the order of drug administration. We scored vocalization (yes or no) and motion $(0=$ no response; $1=$ hop; $2=$ jump; $3=$ run; $4=$ horizontal jump; $5=$ vertical jump) for each shock presentation (scoring based on Bardgett et al, 2003; Schrott and Crnic, 1994).

\section{Statistical Testing}

Data were analyzed using a repeated-measures or two-way analysis of variance (ANOVA), or independent samples $t$-test in the $\mathrm{DH} \beta \mathrm{E}$ - nicotine-alone studies. Tukey's post hoc analysis was used to detect significant differences at $P<0.05$ (SPSS version 13; Chicago, IL).

\section{RESULTS}

\section{Nicotine Infusion into the Dorsal Hippocampus}

The ability of nicotine infusion into the dorsal hippocampus at training and testing, alone or concurrent with training day systemic ethanol administration, to alter contextual and cued fear conditioning was examined. The levels of baseline freezing, measured before the first CS presentation, and immediate freezing, measured after the first CS-US presentation, were similar across all groups. Significant effects of ethanol, $\mathrm{F}(1,27)=99.17, P<0.001$, and nicotine, $\mathrm{F}(1,27)=6.59, P<0.05$, on freezing to the context on testing day were found, but there was no interactive effect of ethanol and nicotine. There was also a significant effect of ethanol on freezing to the $\mathrm{CS}, \mathrm{F}(1,27)=45.67, P<0.001$, but there was no effect of nicotine on freezing to the CS nor was there a significant ethanol by nicotine interaction. There 
were no significant differences in freezing during the pre-CS period (Figure 1).

Post hoc analysis revealed that during context testing, the ethanol-treated groups ( $n=7$ for each) froze significantly less than saline controls $(n=7)$ and less than the nicotine alone group $(n=8)(P<0.001)$. The nicotine alone group froze significantly more to the context than saline controls $(P<0.05)$. For cued fear conditioning, both groups administered systemic ethanol froze significantly less than the saline or the nicotine alone group $(P<0.001)$; no significant difference existed between the nicotine alone group and the saline controls. Thus, nicotine infusion into the dorsal hippocampus enhanced contextual fear conditioning, but failed to ameliorate ethanol-induced learning deficits.

\section{Nicotine Infusion into The Anterior Cingulate}

The ability of nicotine infusion into the anterior cingulate at training and testing, alone or concurrent with training day systemic ethanol administration, to alter contextual and cued fear conditioning was examined next. The levels of baseline and immediate freezing were similar across all groups. Significant effects of ethanol, $\mathrm{F}(1,35)=41.61$, $P<0.001$, and of nicotine, $\mathrm{F}(1,35)=9.21, P<0.01$, on freezing to the context on testing day were found, as well as an interaction of ethanol and nicotine $\mathrm{F}(1,35)=18.57$, $P<0.001$. There were also significant effects of ethanol, $\mathrm{F}(1,35)=31.32, P<0.001$, and of nicotine, $\mathrm{F}(1,35)=9.50$, $P<0.01$, on freezing to the CS, and an interaction of ethanol and nicotine $\mathrm{F}(1,35)=8.58, P<0.01$. There were no significant differences in freezing during the pre-CS period (Figure 2).

Post hoc analysis revealed that during context testing, the ethanol-alone group $(n=10)$ froze significantly less than saline controls $(n=8)$ and less than the nicotine infusion groups $(P<0.001)$. The nicotine alone $(n=8)$ and nicotine and ethanol $(n=9)$ groups were similar to saline controls. The same pattern emerged for cued fear conditioning. Thus, nicotine infusion into the anterior cingulate did not enhance contextual fear conditioning, but ameliorated ethanol-induced deficits in contextual and cued fear conditioning.

\section{Nicotine Administration on Training Day Only}

In the previous studies, nicotine was administered at both training and testing. To test if training day administration of nicotine is sufficient to ameliorate ethanol-induced deficits, nicotine and ethanol were both administered systemically on training day only. Baseline and immediate freezing were similar across all groups. Significant effects of ethanol, $\mathrm{F}(1,36)=215.01, \quad P<0.001$, and of nicotine, $\mathrm{F}(1,36)=8.16, P<0.01$, on freezing to the context on testing day were found, as well as an interaction of ethanol and nicotine $\mathrm{F}(1,36)=4.39, P<0.05$. There were also significant effects of ethanol, $\mathrm{F}(1,36)=26.15, P<0.001$, and of nicotine, $\mathrm{F}(1,36)=4.39, P<0.05$, on freezing to the CS, as well as an interaction of ethanol and nicotine $\mathrm{F}(1,36)=5.54, P<0.05$. There were no significant differences in freezing during the pre-CS period.

Post hoc analysis revealed that for context testing, both ethanol-treated groups froze significantly less than saline controls and the nicotine alone group $(P<0.001)$, but the group administered ethanol and nicotine also froze significantly more than the group administered ethanol alone $(P<0.01)$. The group administered nicotine alone froze at levels similar to saline controls. For cued fear conditioning, the group administered ethanol alone froze significantly less than all other groups $(P<0.01)$. Nicotine groups were not significantly different from saline controls. Thus, systemic nicotine administration on training day only did not enhance contextual fear conditioning, as has previously been shown (Gould and Higgins, 2003a; Gould and Wehner, 1999); but ameliorated ethanol-induced deficits in contextual and cued fear conditioning (Table 1).

Based on the results with systemic nicotine, the effects of nicotine infusion into the anterior cingulate on training day only were assessed. Baseline and immediate freezing were

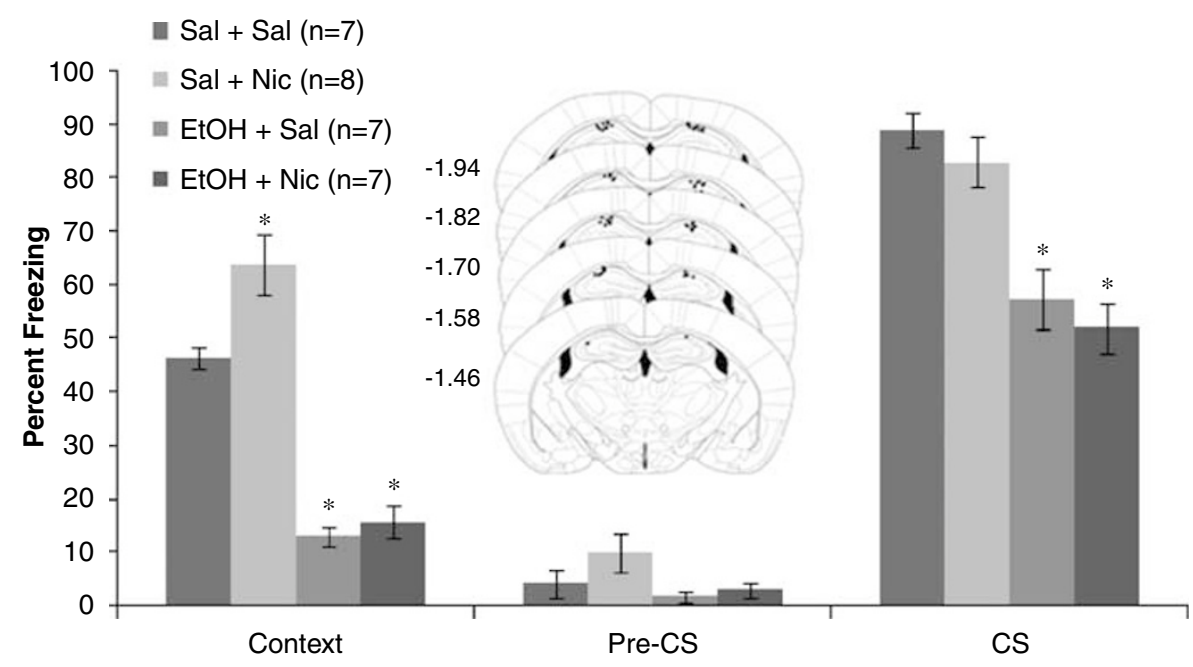

Figure I Bilateral nicotine infusion $(0.35 \mu \mathrm{g} / 0.50 \mu \mathrm{l}$ per side) into the dorsal hippocampus at training and testing enhanced contextual fear conditioning but failed to ameliorate systemic ethanol-induced $(1.0 \mathrm{~g} / \mathrm{kg}$ ) impairments in contextual and cued fear conditioning (mean \pm SEM; * indicates significant difference from controls, $P<0.05)$. Center figure represents drug infusion sites. 


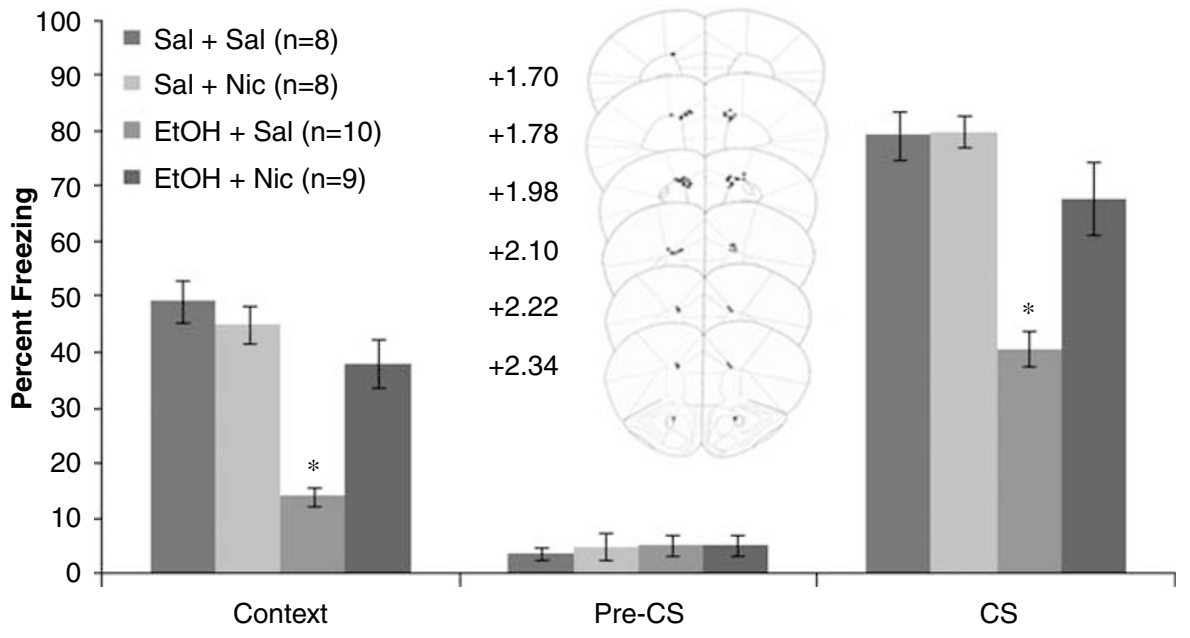

Figure 2 Bilateral nicotine infusion $(0.35 \mu \mathrm{g} / 0.50 \mu \mathrm{l}$ per side) into the anterior cingulate at training and testing ameliorated systemic ethanol-induced $(1.0 \mathrm{~g} / \mathrm{kg})$ impairments in contextual and cued fear conditioning, but failed to enhance contextual fear conditioning (mean \pm SEM; * indicates significant difference from controls, $P<0.05)$. Center figure represents drug infusion sites.

Table I Systemic Nicotine on Training Day Only (mean \pm SEM)

\begin{tabular}{lcccc}
\hline Group & $\begin{array}{c}\text { Saline } \\
\mathbf{n = 1 0}\end{array}$ & $\begin{array}{c}\text { Ethanol } \\
\mathbf{n = 9}\end{array}$ & $\begin{array}{c}\text { Nicotine } \\
\mathbf{n = 1 0}\end{array}$ & $\begin{array}{c}\text { EtOH and nicotine } \\
\mathbf{n = 9}\end{array}$ \\
\hline Context & $46.7 \pm 2.6$ & $16.0 \pm 1.3$ & $45.3 \pm 1.7$ & $24.7 \pm 1.3$ \\
CS & $81.2 \pm 2.6$ & $56.1 \pm 4.4$ & $82.2 \pm 2.9$ & $71.7 \pm 4.6$ \\
\hline
\end{tabular}

similar across all groups. Significant effects of ethanol, $\mathrm{F}(1,28)=35.20, P<0.001$, and of nicotine, $\mathrm{F}(1,28)=23.01$, $P<0.001$, on freezing to the context on testing day were found, as well as an interaction of ethanol and nicotine $\mathrm{F}(1,28)=33.30, P<0.001$. There were also significant effects of ethanol, $\mathrm{F}(1,28)=45.88, P<0.001$, and of nicotine, $\mathrm{F}(1,28)=10.03, P<0.01$, on freezing to the CS, and an interaction of ethanol and nicotine $F(1,28)=31.04$, $P<0.001$. There were no significant differences in freezing during the pre-CS period (Figure 3).

Post hoc analysis revealed that during context testing, the ethanol-alone group $(n=8)$ froze significantly less than saline controls $(n=7)$ and less than the groups infused with nicotine $(n=7$ for each) $(P<0.001)$. The nicotine-infused groups froze at levels similar to saline controls. The same results were seen for cued fear conditioning. Thus, similar to systemic nicotine, nicotine infusion into the anterior cingulate on training day only did not enhance contextual fear conditioning, but ameliorated ethanol-induced deficits in contextual and cued fear conditioning.

To ensure that the effects of nicotine were specific to the anterior cingulate, and not to diffusion into nearby areas, we also infused nicotine below (accessory optic tract) and lateral (motor cortex) to the anterior cingulate. This control was not necessary for the hippocampus study as it was previously conducted in our laboratory (Davis et al, 2007). For both sets of infusions, baseline and immediate freezing were similar across all groups. For the below infusions, there was a significant effect of systemic ethanol on freezing to the context, $\mathrm{F}(1,26)=90.62, P<0.001$, and to the CS,
$\mathrm{F}(1,26)=49.12, P<0.001$, but no other significant effects. Post hoc analysis revealed that during context and cued testing, both ethanol-treated groups $(n=7$ for each) froze significantly less than saline controls $(n=7)$ and the nicotine alone group $(n=8)(P<0.001)$. For the lateral infusions, there was a significant effect of ethanol on freezing to the context, $\mathrm{F}(1,24)=105.87, P<0.001$, and to the CS, $\mathrm{F}(1,24)=257.12, P<0.001$, on testing day, but no other significant effects. Post hoc analysis revealed that during context and cued testing, the ethanol-treated groups ( $n=6$ for EtOH-alone and $n=7$ for Nic and EtOH) froze significantly less than saline controls $(n=7$ for each) and the nicotine-alone group $(n=7)(P<0.001)$ (Figure 4$)$. Thus, nicotine administration below or lateral to the anterior cingulate on training day only did not alter contextual and cued fear conditioning.

\section{$\mathrm{DH} \beta \mathrm{E}$ Blockade of Nicotine Amelioration of Ethanol-Induced Deficits}

To determine whether the high-affinity $\mathrm{nAChR}$ antagonist $\mathrm{DH} \beta \mathrm{E}$ would alter the interactive effects of nicotine and ethanol, we administered nicotine, ethanol, and $\mathrm{DH} \beta \mathrm{E}$ systemically. Baseline and immediate freezing were similar across all groups. A significant effect of drug treatment on freezing to the context on testing day was found, $\mathrm{F}(3,24)=28.35, P<0.001$. There was also a significant effect of drug treatment on freezing to the CS, $F(1,24)=11.74$, $P<0.01$. There were no significant differences in freezing during the pre-CS period. Post hoc tests demonstrated that ethanol decreased freezing below saline control levels for both the contextual and cued tests $(P<0.01)$, but the group treated with ethanol and nicotine froze significantly more than the ethanol-alone group $(P<0.05)$. The group administered $\mathrm{DH} \beta \mathrm{E}$, ethanol, and nicotine froze at similar levels to the ethanol-alone group (Table 2).

To investigate whether the $0.09 \mathrm{mg} / \mathrm{kg}$ nicotine dose and the $6.0 \mathrm{mg} / \mathrm{kg} \mathrm{DH} \beta \mathrm{E}$ dose interact to alter learning in the absence of ethanol, we administered both drugs systemically before training. Baseline freezing and immediate 


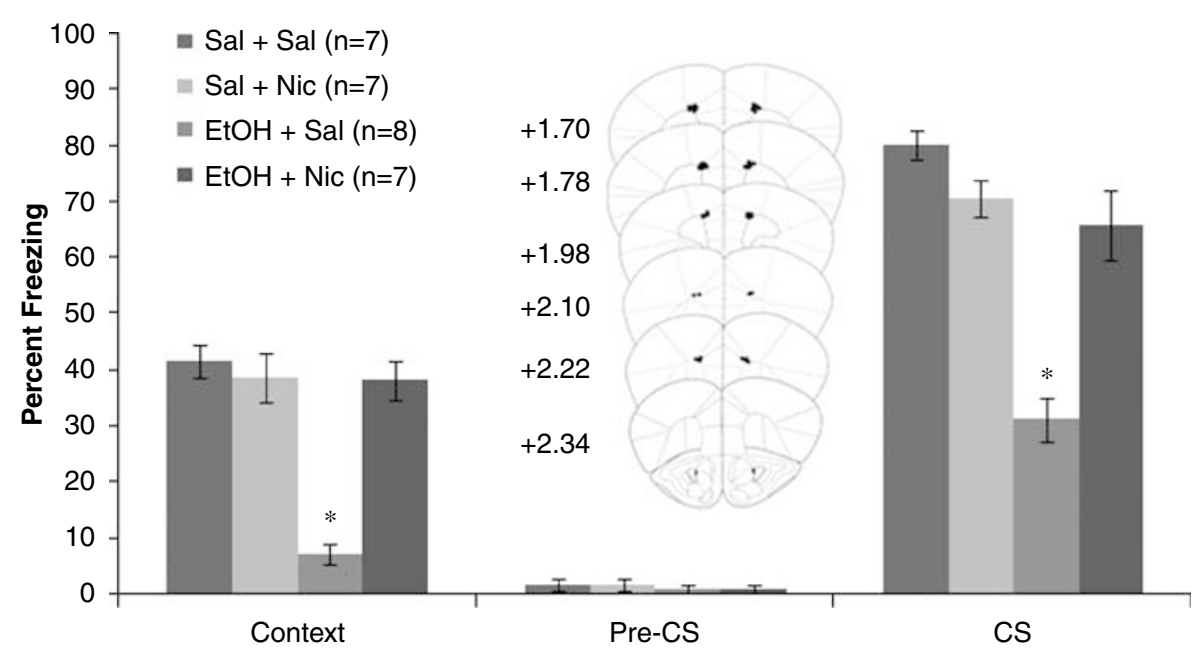

Figure 3 Bilateral nicotine infusion $(0.35 \mu \mathrm{g} / 0.50 \mu \mathrm{l}$ per side) into the anterior cingulate on training day only ameliorated systemic ethanol-induced $(1.0 \mathrm{~g} / \mathrm{kg})$ impairments in contextual and cued fear conditioning but failed to enhance contextual fear conditioning (mean \pm SEM; * indicates significant difference from controls, $P<0.05)$. Center figure represents drug infusion sites.
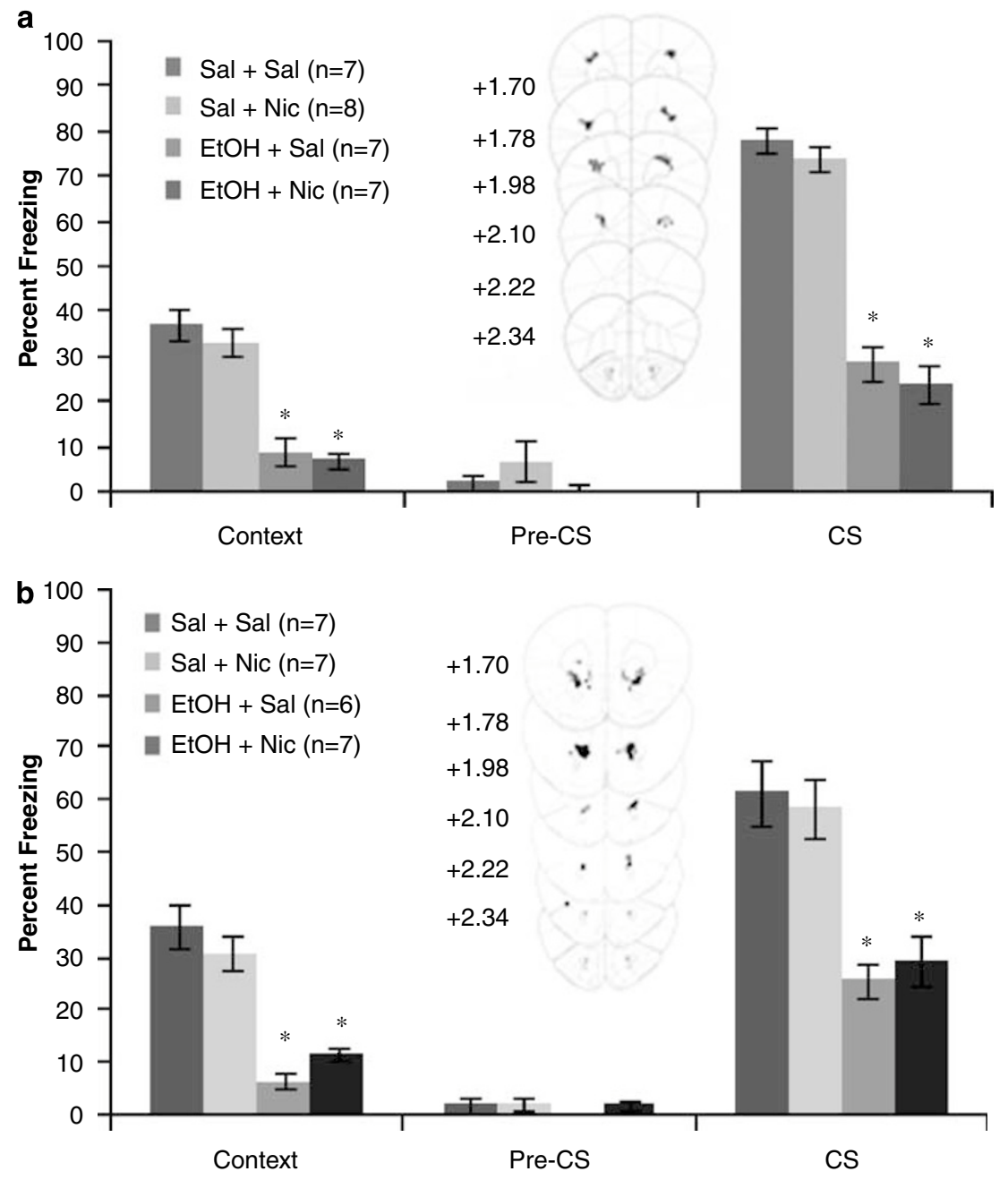

Figure 4 Bilateral nicotine infusion $(0.35 \mu \mathrm{g} / 0.50 \mu \mathrm{l}$ per side) lateral to (a) or below (b) the anterior cingulate had no effect on contextual and cued fear conditioning or on systemic ethanol-induced deficits (mean \pm SEM; $*$ indicates significant difference from controls, $P<0.05$ ). Center figures represent drug infusion sites. 
freezing were similar across all groups. Co-administration nicotine and $\mathrm{DH} \beta \mathrm{E}$ significantly disrupted freezing to the context, $t(12)=1.07, P<0.001$, and freezing to the CS at testing, $t(12)=0.70, P<0.001$ (Table 3 ). There was no effect on freezing during the pre-CS period.

To examine whether the anterior cingulate is essential for the amelioration of ethanol-induced learning deficits by nicotine, we infused $\mathrm{DH} \beta \mathrm{E}$ into the anterior cingulate and administered ethanol and nicotine systemically before training. Baseline and immediate freezing were similar across all groups. There was a significant testing day effect of drug treatment on freezing to the context, $\mathrm{F}(3,22)=35.40, \quad P<0.001$, and on freezing to the CS, $\mathrm{F}(3,22)=10.42, P<0.001$. There were no significant differences in freezing during the pre-CS period (Figure 5).

Post hoc analysis revealed that the ethanol-alone $(n=7)$ and ethanol-nicotine-DH $\beta \mathrm{E}(n=9)$ groups froze significantly less than saline controls $(n=6)$ and the ethanolnicotine group $(n=7)$ to both the context $(P<0.001)$ and the CS $(P<0.01)$. The ethanol-nicotine group was not significantly different from saline controls in either test.

Table 2 Systemic $D H \beta E$, Nicotine, and Ethanol (mean \pm SEM)

\begin{tabular}{lcccc}
\hline Group & $\begin{array}{c}\text { Saline } \\
\mathbf{n}=\mathbf{6}\end{array}$ & $\begin{array}{c}\text { Ethanol } \\
\mathbf{n}=\mathbf{7}\end{array}$ & $\begin{array}{c}\text { EtOH and } \\
\text { nicotine } \boldsymbol{n}=\mathbf{7}\end{array}$ & $\begin{array}{c}\mathbf{D H} \boldsymbol{\beta E}, \text { EtOH } \\
\text { and } \text { nicotine } \boldsymbol{n}=\mathbf{7}\end{array}$ \\
\hline Context & $45.6 \pm 1.5$ & $11.0 \pm 1.7$ & $29.5 \pm 1.2$ & $8.6 \pm 2.1$ \\
CS & $89.8 \pm 2.9$ & $31.8 \pm 4.4$ & $76.2 \pm 5.0$ & $41.3 \pm 4.7$ \\
\hline
\end{tabular}

Table 3 Co-administration of Systemic $\mathrm{DH} \beta$ E and Nicotine (mean $\pm \mathrm{SEM}$ )

\begin{tabular}{lcc}
\hline Group & Saline $\boldsymbol{n}=\mathbf{8}$ & $\mathbf{D H} \boldsymbol{\beta}$ E and nicotine $\boldsymbol{n}=\mathbf{7}$ \\
\hline Context & $32.1 \pm 2.9$ & $7.6 \pm 1.9$ \\
CS & $86.1 \pm 3.0$ & $33.3 \pm 5.7$ \\
\hline
\end{tabular}

Thus, $\mathrm{DH} \beta \mathrm{E}$ infused into the anterior cingulate altered the effects of systemic nicotine on ethanol-induced learning deficits. This suggests that the effects of nicotine in the anterior cingulate are both necessary and sufficient to ameliorate ethanol-induced cognitive impairments.

\section{DH $\beta$ E Amelioration of Ethanol-Induced Deficits}

To determine whether $\mathrm{DH} \beta \mathrm{E}$ may alter learning or ethanolinduced learning deficits in the absence of nicotine, we systemically administered $\mathrm{DH} \beta \mathrm{E}$ and ethanol at training. Baseline and immediate freezing were similar across all groups. There was a significant effect of ethanol, $\mathrm{F}(1,28)=20.44, P<0.001$, but not $\mathrm{DH} \beta \mathrm{E}$, on freezing to the context on testing day. There was a significant interaction of ethanol and $\mathrm{DH} \beta \mathrm{E}$ on freezing to the context, $\mathrm{F}(1,28)=19.17, P<0.001$. There was also a significant effect of ethanol, $\mathrm{F}(1,28)=32.81, \quad P<0.001$, and $\mathrm{DH} \beta \mathrm{E}$, $\mathrm{F}(1,28)=7.81, P<0.05$, on freezing to the CS on testing day, as well as a significant interaction of ethanol and $\mathrm{DH} \beta \mathrm{E}$ on freezing to the CS, $\mathrm{F}(1,28)=22.24, P<0.001$. There were no significant differences in freezing during the pre-CS period.

Post hoc tests revealed that the ethanol-alone group froze significantly less than saline controls to both the context and the CS $(P<0.05)$. The group administered ethanol and $\mathrm{DH} \beta \mathrm{E}$ froze significantly less than the control group to the context $(P<0.05)$, but also froze significantly more to both the context and the CS than the group administered ethanol alone $(P<0.05)$ (Table 4). Thus, systemic DH $\beta$ E partially ameliorated ethanol-induced deficits in fear conditioning.

Table 4 Systemic DH $\beta$ E and Ethanol (mean \pm SEM)

\begin{tabular}{lcccc}
\hline Group & $\begin{array}{c}\text { Saline } \\
\mathbf{n = 6}\end{array}$ & $\begin{array}{c}\text { Ethanol } \\
\mathbf{n}=\mathbf{8}\end{array}$ & $\begin{array}{c}\mathbf{D H} \boldsymbol{\beta E} \\
\mathbf{n = 7}\end{array}$ & $\begin{array}{c}\mathbf{D H} \boldsymbol{\beta} \text { E and EtOH } \\
\mathbf{n = 8}\end{array}$ \\
\hline Context & $43.3 \pm 3.0$ & $13.8 \pm 2.2$ & $30.5 \pm 5.1$ & $30.0 \pm 3.4$ \\
CS & $82.4 \pm 2.4$ & $48.6 \pm 2.7$ & $79.2 \pm 4.3$ & $72.9 \pm 3.8$ \\
\hline
\end{tabular}

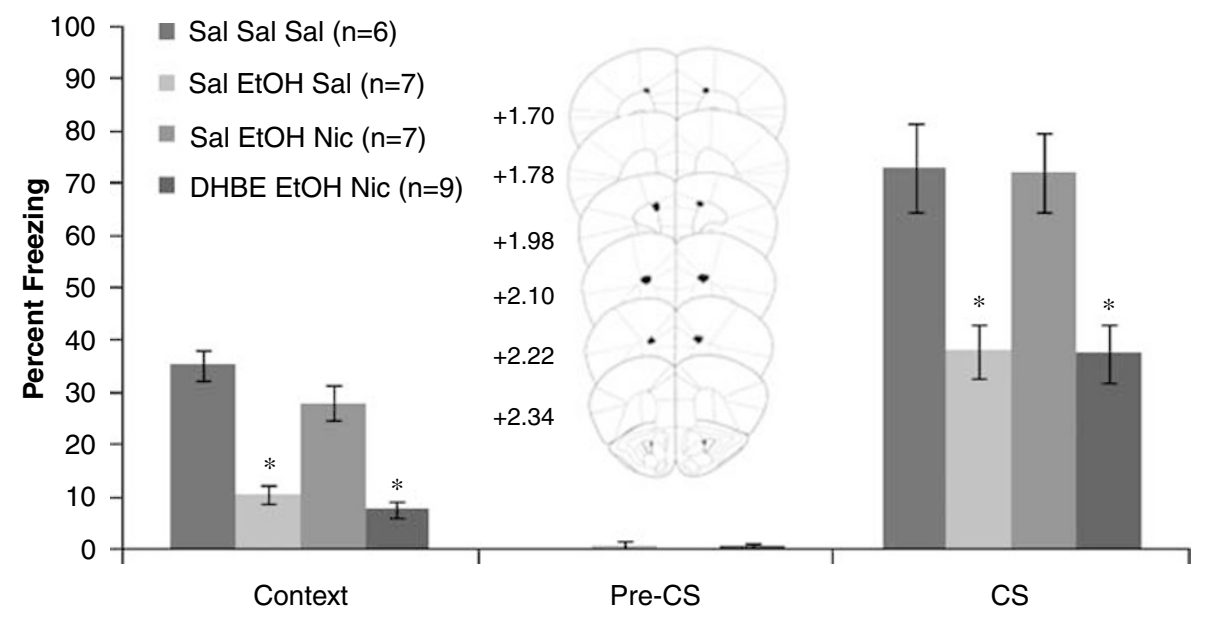

Figure 5 Bilateral $\mathrm{DH} \beta \mathrm{E}$ infusion $(\mid \mathrm{I} .0 \mu \mathrm{g} / 0.50 \mu \mathrm{l}$ per side) into the anterior cingulate altered the effects of systemic nicotine $(0.09 \mathrm{mg} / \mathrm{kg})$ on systemic ethanol-induced $(1.0 \mathrm{~g} / \mathrm{kg})$ impairments in contextual and cued fear conditioning (mean $\pm \mathrm{SEM}$; * indicates significant difference from controls, $P<0.05$ ). Center figure represents drug infusion sites. 


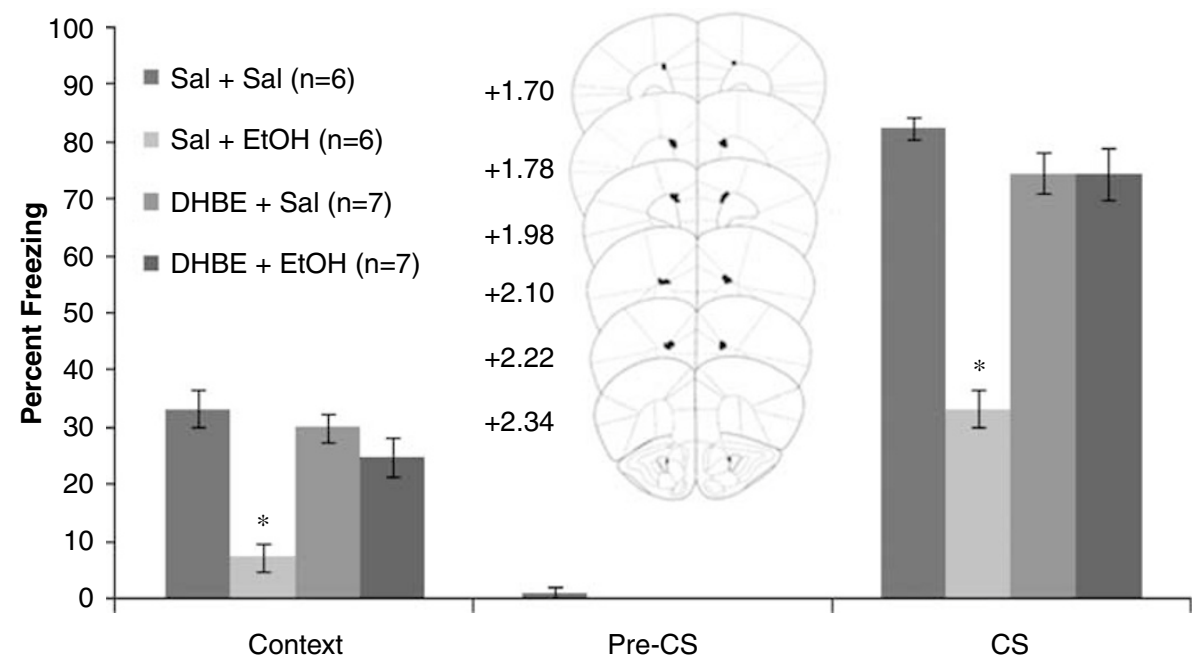

Figure 6 Bilateral $\mathrm{DH} \beta \mathrm{E}$ infusion $(18.0 \mu \mathrm{g} / 0.50 \mu \mathrm{l}$ per side) into the anterior cingulate ameliorated systemic ethanol-induced ( $1.0 \mathrm{~g} / \mathrm{kg})$ impairments in contextual and cued fear conditioning but did not alter contextual or cued fear conditioning when administered alone (mean \pm SEM; * indicates significant difference from controls, $P<0.05$ ).

We next examined whether $\mathrm{DH} \beta \mathrm{E}$ infused into the anterior cingulate alters ethanol-induced learning deficits. Baseline and immediate freezing were similar across all groups. There was a significant effect of ethanol, $\mathrm{F}(1,25)=33.25, P<0.001$, but not $\mathrm{DH} \beta \mathrm{E}$, on freezing to the context on testing day, and a significant interaction of ethanol and $\mathrm{DH} \beta \mathrm{E}, \mathrm{F}(1,25)=14.74, P<0.001$. There was also a significant effect of ethanol, $\mathrm{F}(1,25)=55.17, P<0.001$, and $\mathrm{DH} \beta \mathrm{E}, \mathrm{F}(1,25)=25.67, P<0.05$, on freezing to the CS on testing day, and a significant interaction of ethanol and $\mathrm{DH} \beta \mathrm{E}, \mathrm{F}(1,25)=15.17, P<0.001$. No significant differences in freezing existed during the pre-CS period (Figure 6).

Post hoc tests revealed that the group administered systemic ethanol alone $(n=6)$ froze significantly less to the context and to the CS than saline controls $(n=6)$ $(P<0.05)$. The $\mathrm{DH} \beta \mathrm{E}$ infusion groups $(n=7$ each) were not significantly different from saline controls in freezing to the context or the CS. Thus, infusion of $\mathrm{DH} \beta \mathrm{E}$ into the anterior cingulate cortex ameliorated ethanol-induced learning deficits but did not alter learning in the absence of ethanol.

\section{Amelioration of Ethanol-Induced Deficits by Subthreshold Doses of Nicotine and $\mathrm{DH} \beta \mathrm{E}$}

Because both nicotine and $\mathrm{DH} \beta \mathrm{E}$ ameliorated ethanolinduced deficits, we tested if co-administration of subthreshold doses of each would act synergistically on ethanolinduced deficits. We first determined that a twofold dilution of our effective doses of nicotine $(0.045 \mathrm{mg} / \mathrm{kg})$ and $\mathrm{DH} \beta \mathrm{E}$ $(3.0 \mathrm{mg} / \mathrm{kg})$ would not ameliorate ethanol-induced deficits. For nicotine, baseline and immediate freezing were similar across all groups. At context testing, there was only a significant effect of ethanol, $\mathrm{F}(1,27)=196.68, P<0.001$. There was a significant effect of ethanol, $\mathrm{F}(1,27)=400.34$, $P<0.001$, and nicotine, $\mathrm{F}(1,27)=8.34, P<0.01$, on freezing to the CS, but no interaction. There were no significant differences in freezing during the pre-CS period. Post hoc tests revealed that both groups administered ethanol froze significantly less to both the context and the CS than saline controls $(P<0.05)$, whereas the group administered nico-
Table 5 Ethanol and Subthreshold Doses of Systemic Nicotine or $\mathrm{DH} \beta \mathrm{E}($ mean $\pm \mathrm{SEM})$

EtOH and

Group Saline $n=7$ Ethanol $n=7 \quad$ Nicotine $n=7 \quad$ nicotine $n=7$

\begin{tabular}{lrccc}
\hline Context & $44.3 \pm 2.5$ & $14.3 \pm 2.2$ & $39.1 \pm 2.4$ & $12.4 \pm 1.5$ \\
CS & $81.7 \pm 2.5$ & $38.9 \pm 3.2$ & $89.5 \pm 2.6$ & $44.4 \pm 1.3$ \\
Group & Saline $\boldsymbol{n}=\mathbf{8}$ & Ethanol $\boldsymbol{n}=\mathbf{8}$ & $\mathbf{D H} \beta \mathbf{E} \mathbf{n}=\mathbf{8}$ & $\begin{array}{c}\text { EtOH and } \\
\text { DH } \beta \mathbf{E} \boldsymbol{n}=\mathbf{9}\end{array}$ \\
CS & $45.0 \pm 2.8$ & $16.3 \pm 2.3$ & $29.1 \pm 2.6$ & $13.7 \pm 1.6$ \\
Group & $85.4 \pm 1.6$ & $54.9 \pm 4.8$ & $65.6 \pm 7.0$ & $47.5 \pm 3.4$ \\
\hline
\end{tabular}

tine alone was not significantly different from saline controls (Table 5). Thus, $0.045 \mathrm{mg} / \mathrm{kg}$ nicotine did not ameliorate ethanol-induced learning deficits.

For the $3.0 \mathrm{mg} / \mathrm{kg} \mathrm{DH} \beta \mathrm{E}$ dose, baseline and immediate freezing were similar across all groups. There was a significant effect of ethanol, $\mathrm{F}(1,29)=95.69, P<0.001$, and $\mathrm{DH} \beta \mathrm{E}, \mathrm{F}(1,29)=22.34, P<0.01$, on freezing to the context on testing day, and a significant interaction, $\mathrm{F}(1,29)=12.60$, $P<0.05$. There was a significant effect of ethanol, $\mathrm{F}(1,29)=30.67, \quad P<0.01, \quad$ and $\mathrm{DH} \beta \mathrm{E}, \quad \mathrm{F}(1,29)=10.73$, $P<0.01$, on freezing to the CS, but no significant interaction. There were no significant differences in freezing during the pre-CS period. Post hoc tests revealed that both ethanol groups froze significantly less to both the context and the CS than saline controls $(P<0.05)$, as did the group administered $\mathrm{DH} \beta \mathrm{E}$ alone (Table 5). Thus, $3.0 \mathrm{mg} / \mathrm{kg} \mathrm{DH} \beta \mathrm{E}$ did not ameliorate ethanol-induced learning deficits.

We next co-administered the subthreshold, systemic doses of both drugs with ethanol at training. Baseline and immediate freezing were similar across all groups. On testing day, there was a significant effect of drug treatment on freezing to the context, $\mathrm{F}(2,19)=30.34, P<0.001$, and the CS, $\mathrm{F}(2,19)=27.54, P<0.001$. There were no significant differences in freezing during the pre-CS period (Figure 7). 


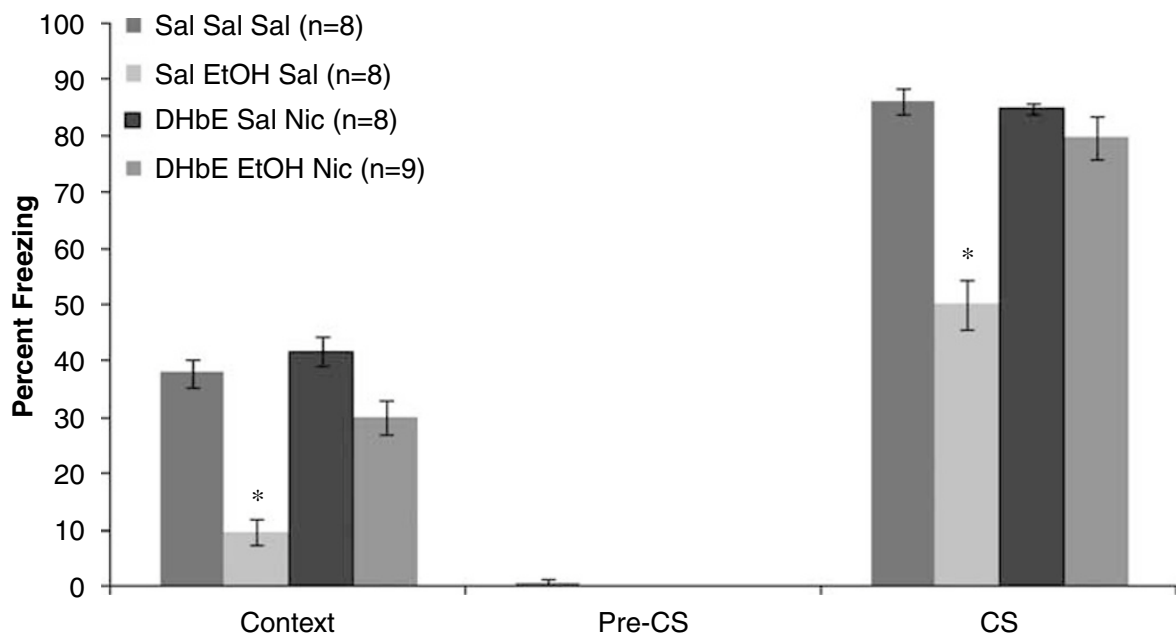

Figure 7 Co-administration of subthreshold systemic doses of $\mathrm{DH} \beta \mathrm{E}(3.0 \mathrm{mg} / \mathrm{kg})$ and nicotine $(0.045 \mathrm{mg} / \mathrm{kg})$ ameliorated systemic ethanol-induced (I.0 g/ $\mathrm{kg}$ ) impairments in contextual and cued fear conditioning but did not alter conditioning in the absence of ethanol (mean \pm SEM; * indicates significant difference from controls, $P<0.05)$.

Post hoc analysis revealed that only the ethanol-alone group $(n=8)$ froze significantly less than saline controls $(n=8)$ to the context and to the CS $(P<0.001)$. The group administered $\mathrm{DH} \beta \mathrm{E}$, ethanol, and nicotine $(n=9)$ and the group administered $\mathrm{DH} \beta \mathrm{E}$ and nicotine $(n=8)$ were not significantly different from saline controls. Thus, coadministration of subthreshold doses of $\mathrm{DH} \beta \mathrm{E}$ and nicotine-ameliorated ethanol-induced learning deficits.

To determine whether co-administration of systemic subthreshold doses of nicotine and $\mathrm{DH} \beta \mathrm{E}$ could enhance learning in the absence of ethanol, mimicking the effect of nicotine on contextual fear conditioning, $\mathrm{DH} \beta \mathrm{E}$ and nicotine were administered before training and testing. Baseline and immediate freezing were similar across all groups. There was no significant drug effect on freezing to the context on testing day, but a significant effect of drug treatment on freezing to the CS on testing day, $t(14)=3.04$, $P<0.05$; the group administered nicotine and $\mathrm{DH} \beta \mathrm{E}$ froze significantly less than the saline group to the CS (Table 6). Thus, co-administration of subthreshold doses of $\mathrm{DH} \beta \mathrm{E}$ and nicotine do not enhance learning, suggesting that the enhancement of contextual fear conditioning and the amelioration of ethanol-induced deficits in contextual and cued fear conditioning by nicotine occur through different processes.

\section{DH $\beta$ E Fails to Ameliorate Ethanol-Induced Deficits in B2 Knockout Mice}

To determine whether $\beta 2$-containing receptors are involved in the $\mathrm{DH} \beta \mathrm{E}$ amelioration of ethanol-induced learning deficits, we co-administered systemic $\mathrm{DH} \beta \mathrm{E}$ and ethanol to $\beta 2 \mathrm{KO}$ and WT mice. Baseline and immediate freezing were similar across all groups. There was a significant effect of drug, $\quad \mathrm{F}(2,34)=49.17, \quad P<0.001, \quad$ and genotype, $\mathrm{F}(1,35)=20.59, P<0.001$, and a significant interaction on freezing to the context on testing day, $\mathrm{F}(2,34)=17.98$, $P<0.001$. For freezing to the CS on testing day, there was a significant effect of drug, $\mathrm{F}(2,34)=45.41, P<0.001$, and genotype, $\mathrm{F}(1,35)=19.72, \quad P<0.001$, and a significant
Table 6 Co-administration of Systemic Subthreshold Doses of Nicotine and $\mathrm{DH} \beta \mathrm{E}$ (mean $\pm \mathrm{SEM})$

\begin{tabular}{lcc}
\hline Group & Saline $\boldsymbol{n}=\mathbf{8}$ & $\mathbf{D H} \boldsymbol{\beta E}$ and nicotine $\boldsymbol{n}=\mathbf{8}$ \\
\hline Context & $32.3 \pm 3.2$ & $27.1 \pm 1.7$ \\
CS & $90.3 \pm 2.7$ & $79.9 \pm 2.5$ \\
\hline
\end{tabular}

interaction, $F(2,34)=10.70, \quad P<0.001$. There were no significant differences in freezing during the pre-CS period (Figure 8).

Post hoc tests revealed that the WT $(n=7)$ and KO $(n=7)$ saline controls froze at similar levels to both the context and the CS. The groups administered ethanol alone (WT, $n=7$; $\mathrm{KO}, n=8)$ froze significantly less than saline controls in both tests $(P<0.05)$, but there were no differences between genotypes in the effect of ethanol. In the WT mice $(n=7)$, $\mathrm{DH} \beta \mathrm{E}$ ameliorated the ethanol-induced deficit in both tests $(P<0.05)$. No such effect was seen in the KO mice $(n=7)$. Thus, a $\beta 2$-containing nAChR, such as the $\alpha 4 \beta 2 *$ receptor, is involved in the $\mathrm{DH} \beta \mathrm{E}$ amelioration of ethanol-induced learning impairments.

\section{Effects of Ethanol and Nicotine on Shock Sensitivity}

Finally, we examined whether changes in sensitivity to the foot shock may underlie the effects of ethanol or nicotine on fear conditioning. Repeated-measures ANOVA revealed no significant effect of treatment order on motor responding or the number of vocalizations, so we collapsed across days. There were significant effects of shock intensity on motor responding, $\mathrm{F}(7,280)=477.75, P<0.05$, and vocalization, $\mathrm{F}(7,280)=134.19, P<0.05$, but no drug effects or interactions ( $n=12$ for all groups; Figure 9). Thus, neither ethanol nor nicotine significantly altered responding to the shock. 


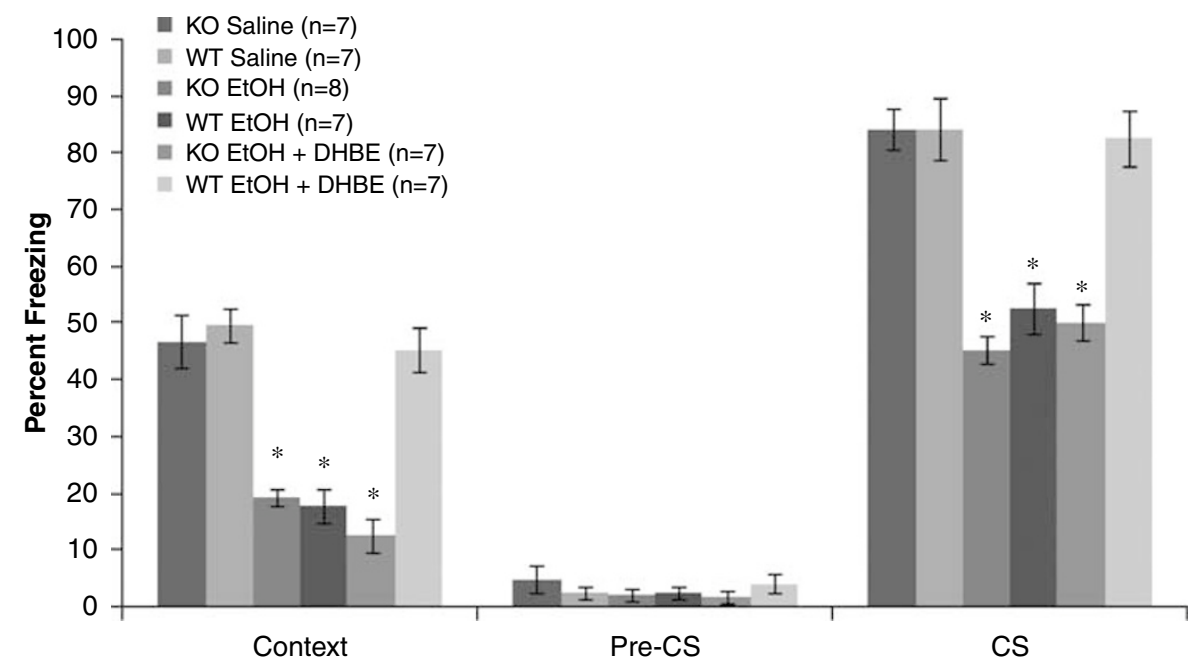

Figure 8 Systemic DH $\beta$ E $(6.0 \mathrm{mg} / \mathrm{kg})$ ameliorated systemic ethanol-induced $(1.0 \mathrm{~g} / \mathrm{kg})$ impairments in contextual and cued fear conditioning in wild-type mice, but failed to ameliorate these deficits in $\beta 2$-knockout mice. There were no other differences between the genotypes in their responses to the drugs (mean \pm SEM; * indicates significant difference from controls, $P<0.05$ ).

\section{DISCUSSION}

Nicotine enhancement of learning and amelioration of ethanol-associated learning deficits are mediated by different neural processes. High-affinity nAChRs in the dorsal hippocampus are involved in the enhancement of contextual fear conditioning by nicotine, whereas high-affinity nAChRs in the anterior cingulate mediate the effects of nicotine on ethanol-induced deficits in contextual and cued fear conditioning. Moreover, nicotine may enhance learning by activating $\beta 2$-containing hippocampal nAChRs but ameliorate ethanol-induced learning deficits by inactivating $\beta 2$-containing anterior cingulate nAChRs.

The dorsal hippocampus processes contextual information during fear conditioning (Esclassan et al, 2009; Maren et al, 1997; Otto and Poon, 2006; Phillips and LeDoux, 1994). Previous research has demonstrated that nicotine infusion into the dorsal hippocampus enhances contextual, but not cued fear conditioning (Davis et al, 2007), demonstrating that the dorsal hippocampus is sufficient for the effects of nicotine on contextual fear conditioning. If nicotine is given systemically and the high-affinity $\mathrm{nAChR}$ antagonist $\mathrm{DH} \beta \mathrm{E}$ is infused into the dorsal hippocampus, no enhancement of contextual fear conditioning is seen (Davis et al, 2007), demonstrating that the dorsal hippocampus is necessary for the enhancement of contextual fear conditioning. However, if nicotine is infused into the dorsal hippocampus of ethanol-treated mice, there is no amelioration of the ethanol-induced deficits in contextual and cued fear conditioning.

In contrast, infusion of nicotine into the anterior cingulate cortex ameliorated ethanol-induced deficits in cued and contextual fear conditioning but had no effect in ethanol-naive mice. Furthermore, infusion of $\mathrm{DH} \beta \mathrm{E}$ into the anterior cingulate disrupted the effects of systemic nicotine on the ethanol-induced deficits. In addition, infusion of nicotine ventral or lateral to the anterior cingulate cortex had no effect on ethanol-induced deficits in fear conditioning, and neither nicotine nor ethanol changed sensitivity to the foot shock. Together these studies suggest that the anterior cingulate cortex is necessary and sufficient for the effects of nicotine on ethanol-induced deficits in fear conditioning.

The anterior cingulate cortex is involved in attention and cognitive control (Cohen et al, 1999; Posner and Rothbart, 1998; Ridderinkhof et al, 2004). Ethanol-induced changes in these or other cingulate-mediated processes could alter fear conditioning. In support, numerous studies have demonstrated a link between the cingulate cortex and fear conditioning. In one study, lesions of the anterior cingulate cortex did not disrupt standard cued fear conditioning but did disrupt trace fear conditioning when tested $24 \mathrm{~h}$ after training (Han et al, 2003). However, another study found that lesions of the anterior cingulate cortex disrupted cued but not contextual fear conditioning when testing occurred $24 \mathrm{~h}$ after training (Bissiere et al, 2008). In addition, the same study found that disruption of anterior cingulate cortical function through infusion of the $\mathrm{GABA}_{\mathrm{a}}$ antagonist muscimol altered cued fear conditioning (the effects on contextual fear conditioning were not reported). Similarly, Tang et al (2005) reported that infusion of the NMDA receptor antagonist APV into the anterior cingulate cortex disrupted cued fear conditioning only, but infusion of muscimol disrupted both cued and contextual fear conditioning 1 and 3 days post training. Furthermore, infusion of the muscarinic cholinergic agonist oxotremorine into the anterior cingulate cortex post training enhanced foot-shock US-related learning (Malin and McGaugh, 2006). Finally, Frankland et al (2004) demonstrated the involvement of this area in remote (36 days old) fear conditioning memories. These results suggest that in addition to being involved in remote fear conditioning memories, the anterior cingulate cortex modulates the early phase of fear conditioning such that disruption of anterior cingulate cortical function during this stage may be detrimental to fear conditioning. Therefore, ethanol may disrupt anterior cingulate function, resulting in a deficit in fear conditioning, 

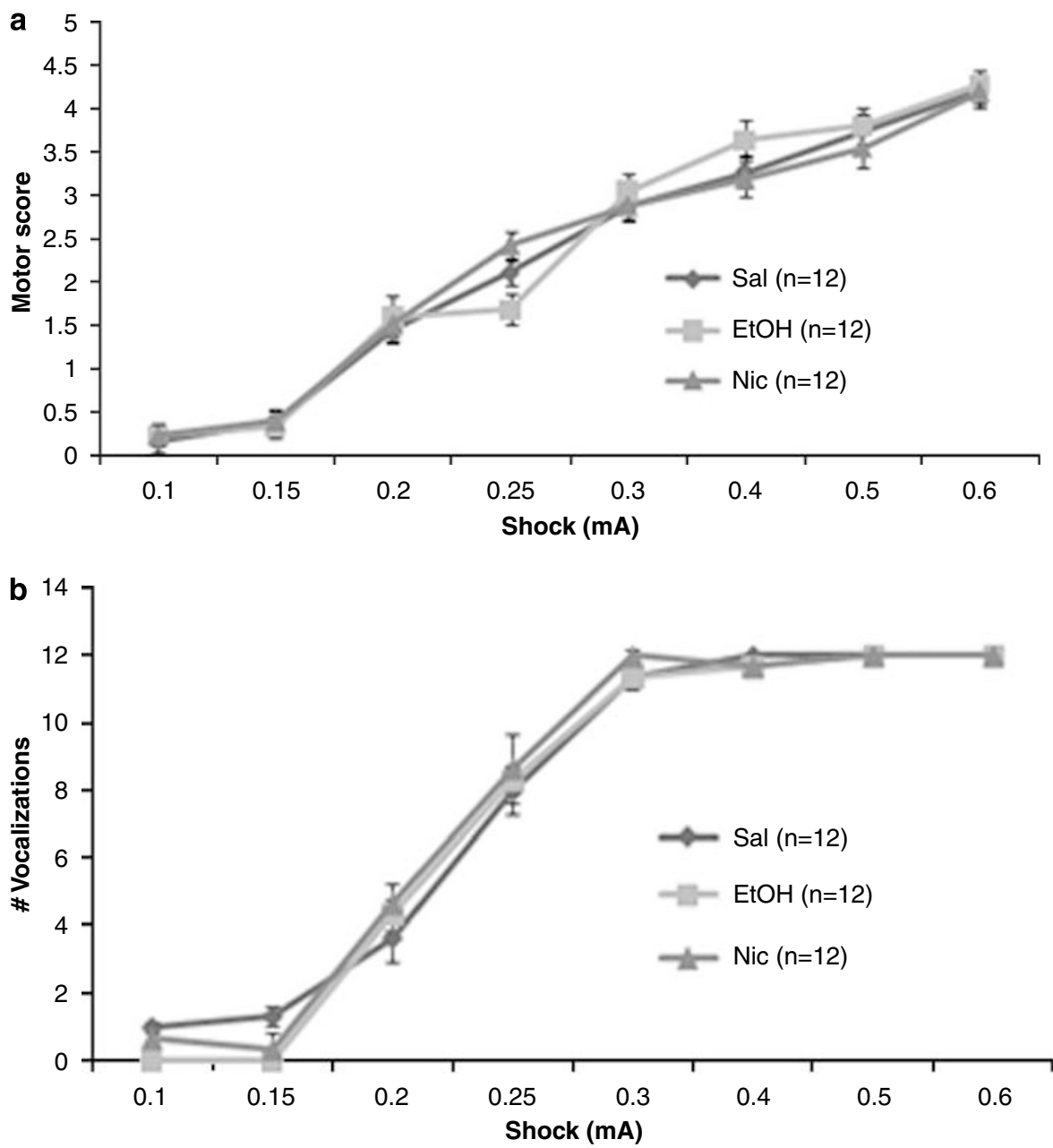

Figure 9 Effects of systemic saline, ethanol $(1.0 \mathrm{~g} / \mathrm{kg})$, or nicotine $(0.09 \mathrm{mg} / \mathrm{kg})$ on shock sensitivity. There were no significant differences between groups in motor behavior (mean \pm SEM) (a) or in vocalizations (\# vocalizations \pm SEM) (b) at any shock intensity.

and nicotine administration may counter this effect of ethanol.

Equally important as identifying the brain areas involved in the interactive effects of nicotine and ethanol on learning is identifying the receptor-level changes that underlie these effects. The effects of nicotine at nAChRs are complex, as nicotine can both activate and desensitize nAChRs, and these effects vary across receptor subtypes (Picciotto et al, 2008). $\alpha 4 \beta 2 \star n A C h R s$ are high-affinity receptors that make up the majority of neuronal nAChRs (Whiting and Lindstrom, 1986a; Whiting and Lindstrom, 1986b). Previous work and this study suggest that nicotine enhances contextual fear conditioning by activating or activating and then desensitizing $\beta 2$-containing nAChRs in the dorsal hippocampus (Davis and Gould, 2006), as the effects of nicotine on contextual fear conditioning are different than the effects of $\mathrm{nAChR}$ antagonists. $\beta 2$-containing $\mathrm{nAChRs}$ also mediate the amelioration of ethanol-induced learning deficits by nicotine (Wehner et al, 2004), but the current findings suggest that these effects may involve nAChR inactivation. Just as nicotine ameliorated ethanol-induced deficits in fear conditioning, infusion of the nAChR antagonist $\mathrm{DH} \beta \mathrm{E}$ into the anterior cingulate ameliorated ethanol-induced learning deficits. The effects of $\mathrm{DH} \beta \mathrm{E}$ on ethanol-induced deficits in fear conditioning involve $\beta 2$-containing $\mathrm{nAChRs}$ as $\beta 2 \mathrm{KO}$ mice did not show $\mathrm{DH} \beta \mathrm{E}$ amelioration of ethanol-induced learning deficits. Furthermore, co-administration of subthreshold doses of $\mathrm{DH} \beta \mathrm{E}$ and nicotine ameliorated ethanol-induced learning deficits, suggesting that nicotine and $\mathrm{DH} \beta \mathrm{E}$ may act synergistically on the ethanol-induced deficits. This interaction may have a dose-dependent inverted U-shaped function as co-administration of higher doses of nicotine and $\mathrm{DH} \beta \mathrm{E}$ disrupted fear conditioning. The mechanism through which nicotine ameliorates ethanol-induced deficits in fear conditioning is still unknown but may involve the depression of nAChR activity as $\mathrm{DH} \beta \mathrm{E}$ and nicotine had similar effects.

An important issue that needs further study is how a decrease of nAChR activity in the cingulate cortex could ameliorate ethanol-induced deficits in fear conditioning. Perhaps ethanol disrupts fear conditioning by increasing nAChR activity in the cingulate cortex. Whereas ethanolinduced upregulation of nAChR activity in the cingulate cortex has not been directly observed, it has been shown that ethanol potentiates $\alpha 4 \beta 2$-like nAChR currents in rat frontal cortical cell cultures (Aistrup et al, 1999; Marszalec et al, 1999). If ethanol is decreasing learning by 
over-activating nAChRs, then a decrease in nAChR activity through nicotine desensitization of the receptors or through inhibition of the receptors by the $\mathrm{nAChR}$ antagonist $\mathrm{DH} \beta \mathrm{E}$ could return the system to a level of activity optimal for learning. The finding that $\mathrm{DH} \beta \mathrm{E}$ blocks the effects of ethanol on fear conditioning supports this theory; however, the finding that $\beta 2 \mathrm{KO}$ mice show ethanol-induced deficits in fear conditioning (Wehner et al, 2004 and present results) suggests this may not be the case. It is possible that an unknown developmental compensatory change in the $\beta 2$ KO mice alters the mechanism underlying ethanol effects on fear conditioning allowing ethanol to disrupt fear conditioning. Alternatively, ethanol and nicotine/ $\mathrm{DH} \beta \mathrm{E}$ may act on separate processes that have opposing actions on a common downstream target.

Interestingly, imaging studies in humans have shown that nicotine and ethanol have opposite effects on cingulate activity (Ghatan et al, 1998; Schreckenberger et al, 2004). In addition, a single nucleotide polymorphism in the gene CHRNA4 was associated with changes in attention-related activity in the anterior cingulate cortex (Winterer et al, 2007). This complements our finding that high-affinity nAChRs (which could include $\alpha 4 \beta 2^{*}$ nAChRs) in the cingulate cortex are involved in the effects of nicotine on ethanol-induced deficits in fear conditioning. However, the cellular location and the processes mediated by these nAChRs remain to be determined. Picciotto et al (2008) put forward a model where nicotine desensitization of nAChRs on GABAergic interneurons in the ventral tegmental area underlies the behavioral effects of nicotine on reward and mood; thus, GABAergic interneurons in the cingulate cortex could similarly be involved in the effects of nicotine on ethanol-induced deficits in fear conditioning. This, however, remains to be tested as presynaptic nAChR regulation of the release of other neurotransmitters, such as dopamine, is also a viable mechanism (see Exley and Cragg, 2008 for a discussion of nAChR activation and inactivation mediating dopamine tone).

In summary, the effects of nicotine on learning in ethanol-naive and ethanol-treated mice are mediated by different brain regions and different $\mathrm{nAChR}$ processes. Nicotine enhances contextual fear conditioning through either activation or activation followed by desensitization of hippocampal $\beta 2$-containing nAChR. In comparison, nicotine acts in the anterior cingulate to ameliorate ethanolinduced deficits in fear conditioning. This amelioration may depend on inactivation of $\beta 2$-containing nAChRs, as nicotine and the $\mathrm{nAChR}$ antagonist $\mathrm{DH} \beta \mathrm{E}$ have similar effects on the ethanol-induced deficits. Thus, inactivation of nAChRs in the cingulate cortex could ameliorate ethanolinduced deficits in fear conditioning by countering the effects of ethanol in the cingulate cortex or in areas efferent of the cingulate cortex.

\section{ACKNOWLEDGEMENTS}

This work was supported by National Institute on Alcohol Abuse and Alcoholism (NIAAA) Grant AA015515 (TJG) and National Institute for Drug Abuse (NIDA) Grant DA01794901 (TJG). All research complies with current US laws for the care and use of laboratory animals.

\section{DISCLOSURE/CONFLICT OF INTEREST}

Danielle Gulick has no conflict of interest to disclose for the research reported herein. Thomas J Gould has no conflict of interest to disclose for the research reported herein.

\section{REFERENCES}

Aistrup GL, Marszalec W, Narahashi T (1999). Ethanol modulation of nicotinic acetylcholine receptor currents in cultured cortical neurons. Mol pharmacol 55: 39-49.

Alkondon M, Albuquerque EX (1993). Diversity of nicotinic acetylcholine receptors in rat hippocampal neurons. I. Pharmacological and functional evidence for distinct structural subtypes. J pharmacol exp ther 265: 1455-1473.

Allman JM, Hakeem A, Erwin JM, Nimchinsky E, Hof P (2001). The anterior cingulate cortex. The evolution of an interface between emotion and cognition. Ann N Y Acad Sci 935: 107-117.

Bardgett ME, Boeckman R, Krochmal D, Fernando H, Ahrens R, Csernansky JG (2003). NMDA receptor blockade and hippocampal neuronal loss impair fear conditioning and position habit reversal in C57Bl/6 mice. Brain Res Bull 60: 131-142.

Bissiere S, Plachta N, Hoyer D, McAllister KH, Olpe HR, Grace AA et al (2008). The rostral anterior cingulate cortex modulates the efficiency of amygdala-dependent fear learning. Biol Psychiatry 63: 821-831.

Blanchard RJ, Magee L, Veniegas R, Blanchard DC (1993). Alcohol and anxiety: ethopharmacological approaches. Prog Neuropsychopharmacol Biol Psychiatry 17: 171-182.

Chiba AA, Kesner RP, Gibson CJ (1997). Memory for temporal order of new and familiar spatial location sequences: role of the medial prefrontal cortex. Learn Mem 4: 311-317.

Cohen RA, Kaplan RF, Moser DJ, Jenkins MA, Wilkinson H (1999). Impairments of attention after cingulotomy. Neurology 53: 819-824.

Davis JA, Gould TJ (2006). The effects of DHBE and MLA on nicotine-induced enhancement of contextual fear conditioning in C57BL/6 mice. Psychopharmacology 184: 345-352.

Davis JA, Kenney JW, Gould TJ (2007). Hippocampal alpha4beta2 nicotinic acetylcholine receptor involvement in the enhancing effect of acute nicotine on contextual fear conditioning. J Neurosci 27: 10870-10877.

Dawson DA (2000). Drinking as a risk factor for sustained smoking. Drug alcohol depend 59: 235-249.

Decker MW, Brioni JD, Bannon AW, Arneric SP (1995). Diversity of neuronal nicotinic acetylcholine receptors: lessons from behavior and implications for CNS therapeutics. Life sci 56: 545-570.

Escher T, Mittleman G (2004). Effects of ethanol and GABAB drugs on working memory in C57BL/6J and DBA/2J mice. Psychopharmacology 176: 166-174.

Esclassan F, Coutureau E, Di Scala G, Marchand AR (2009). Differential contribution of dorsal and ventral hippocampus to trace and delay fear conditioning. Hippocampus 19: 33-44.

Exley R, Cragg SJ (2008). Presynaptic nicotinic receptors: a dynamic and diverse cholinergic filter of striatal dopamine neurotransmission. Br J Pharmacol 153: S283-S297.

Faw B (2003). Pre-frontal executive committee for perception, working memory, attention, long-term memory, motor control, and thinking: a tutorial review. Conscious Cogn 12: 83-139.

Frankland PW, Bontempi B, Talton LE, Kaczmarek L, Silva AJ (2004). The involvement of the anterior cingulate cortex in remote contextual fear memory. Science (New York, NY) 304: 881-883.

Ghatan PH, Ingvar M, Eriksson L, Stone-Elander S, Serrander M, Ekberg $\mathrm{K}$ et al (1998). Cerebral effects of nicotine during 
cognition in smokers and non-smokers. Psychopharmacology 136: $179-189$.

Gould TJ (2003). Ethanol disrupts fear conditioning in C57BL/6 mice. J Psychopharmacol (Oxford, England) 17: 77-81.

Gould TJ, Higgins SJ (2003a). Nicotine enhances contextual fear conditioning in $\mathrm{C} 57 \mathrm{BL} / 6 \mathrm{~J}$ mice at 1 and 7 days post-training. Neurobiol learn mem 80: 147-157.

Gould TJ, Lommock JA (2003b). Nicotine enhances contextual fear conditioning and ameliorates ethanol-induced deficits in contextual fear conditioning. Behav Neurosci 117: 1276-1282.

Gould TJ, Wehner JM (1999). Nicotine enhancement of contextual fear conditioning. Behav brain res 102: 31-39.

Gulick D, Gould TJ (2007). Acute ethanol has biphasic effects on short- and long-term memory in both foreground and background contextual fear conditioning in C57BL/6 mice. Alcoholism, Clin Exp Res 31: 1528-1537.

Gulick D, Gould TJ (2008). Interactive effects of ethanol and nicotine on learning in C57BL/6J mice depend on both dose and duration of treatment. Psychopharmacology 196: 483-495.

Han CJ, O’Tuathaigh CM, van Trigt L, Quinn JJ, Fanselow MS, Mongeau $\mathrm{R}$ et al (2003). Trace but not delay fear conditioning requires attention and the anterior cingulate cortex. Proc Natl Acad Sci USA 100: 13087-13092.

Harvey SC, Maddox FN, Luetje CW (1996). Multiple determinants of dihydro-beta-erythroidine sensitivity on rat neuronal nicotinic receptor alpha subunits. J Neurochem 67: 1953-1959.

Johansen JP, Fields HL, Manning BH (2001). The affective component of pain in rodents: direct evidence for a contribution of the anterior cingulate cortex. Proc Natl Acad Sci USA 98: 8077-8082.

John U, Hapke U, Rumpf HJ (2003). A new measure of the alcohol dependence syndrome: the severity scale of alcohol dependence. Eur Addict res 9: 87-93.

Larsson A, Engel JA (2004). Neurochemical and behavioral studies on ethanol and nicotine interactions. Neurosci biobehav rev 27: 713-720.

Logue SF, Paylor R, Wehner JM (1997). Hippocampal lesions cause learning deficits in inbred mice in the Morris water maze and conditioned-fear task. Behav Neurosci 111: 104-113.

Malin EL, Ibrahim DY, Tu JW, McGaugh JL (2007). Involvement of the rostral anterior cingulate cortex in consolidation of inhibitory avoidance memory: interaction with the basolateral amygdala. Neurobiol learn mem 87: 295-302.

Malin EL, McGaugh JL (2006). Differential involvement of the hippocampus, anterior cingulate cortex, and basolateral amygdala in memory for context and footshock. Proc Natl Acad Sci USA 103: 1959-1963.

Maren S, Aharonov G, Fanselow MS (1997). Neurotoxic lesions of the dorsal hippocampus and Pavlovian fear conditioning in rats. Behav brain res 88: 261-274.

Marszalec W, Aistrup GL, Narahashi T (1999). Ethanol-nicotine interactions at alpha-bungarotoxin-insensitive nicotinic acetylcholine receptors in rat cortical neurons. Alcoholism, clin exp res 23: $439-445$.

NIH (2007). http://pubs.niaaa.nih.gov/publications/AA71/AA71. htm.

Otto T, Poon P (2006). Dorsal hippocampal contributions to unimodal contextual conditioning. J Neurosci 26: 6603-6609.

Paxinos G, Franklin K (2001). The Mouse Brain in Stereotaxic Coordinates. Academic: San Diego, pp 13-45.

Phillips RG, LeDoux JE (1992). Differential contribution of amygdala and hippocampus to cued and contextual fear conditioning. Behav Neurosci 106: 274-285.
Phillips RG, LeDoux JE (1994). Lesions of the dorsal hippocampal formation interfere with background but not foreground contextual fear conditioning. Learn mem 1: 34-44.

Picciotto MR, Addy NA, Mineur YS, Brunzell DH (2008). It is not 'either/or': activation and desensitization of nicotinic acetylcholine receptors both contribute to behaviors related to nicotine addiction and mood. Prog neurobiol 84: 329-342.

Picciotto MR, Brunzell DH, Caldarone BJ (2002). Effect of nicotine and nicotinic receptors on anxiety and depression. Neuroreport 13: 1097-1106.

Pichika R, Easwaramoorthy B, Collins D, Christian BT, Shi B, Narayanan TK et al (2006). Nicotinic alpha4beta2 receptor imaging agents: part II Synthesis and biological evaluation of 2[18F]fluoro-3-[2 3 pyrrolinyl methoxy]pyridine (18F-nifene) in rodents and imaging by PET in nonhuman primate. Nucl med biol 33: 295-304.

Portugal GS, Kenney JW, Gould TJ (2008). beta2 subunit containing acetylcholine receptors mediate nicotine withdrawal deficits in the acquisition of contextual fear conditioning. Neurobiol learn mem 89: 106-113 e-pub ahead of print 20 June 2007.

Posner MI, Rothbart MK (1998). Attention, self-regulation and consciousness. Philos trans R Soc Lond 353: 1915-1927.

Raybuck JD, Gould TJ (2009). Nicotine withdrawal-induced deficits in trace fear conditioning in C57BL/6 mice-a role for high-affinity beta2 subunit-containing nicotinic acetylcholine receptors. Eur J Neurosci 29: 377-387.

Ridderinkhof KR, Ullsperger M, Crone EA, Nieuwenhuis S (2004). The role of the medial frontal cortex in cognitive control. Science (New York, NY) 306: 443-447.

Salas R, Pieri F, De Biasi M (2004). Decreased signs of nicotine withdrawal in mice null for the beta4 nicotinic acetylcholine receptor subunit. J Neurosci 24: 10035-10039.

Schreckenberger M, Amberg R, Scheurich A, Lochmann M, Tichy W, Klega A et al (2004). Acute alcohol effects on neuronal and attentional processing: striatal reward system and inhibitory sensory interactions under acute ethanol challenge. Neuropsychopharmacology 29: 1527-1537.

Schrott LM, Crnic LS (1994). Sensitivity to foot shock in autoimmune NZB $\times$ NZW F1 hybrid mice. Physiol behav 56: 849-853.

Tang J, Ko S, Ding HK, Qiu CS, Calejesan AA, Zhuo M (2005). Pavlovian fear memory induced by activation in the anterior cingulate cortex. Mol pain 1: 6 .

Wehner JM, Keller JJ, Keller AB, Picciotto MR, Paylor R, Booker TK et al (2004). Role of neuronal nicotinic receptors in the effects of nicotine and ethanol on contextual fear conditioning. Neuroscience 129: 11-24.

White NM (1996). Addictive drugs as reinforcers: multiple partial actions on memory systems. Addiction (Abingdon, England) 91: 921-949; discussion 951-965.

Whiting P, Lindstrom J (1986a). Pharmacological properties of immuno-isolated neuronal nicotinic receptors. J Neurosci 6: 3061-3069.

Whiting PJ, Lindstrom JM (1986b). Purification and characterization of a nicotinic acetylcholine receptor from chick brain. Biochemistry 25: 2082-2093.

Williams M, Robinson JL (1984). Binding of the nicotinic cholinergic antagonist, dihydro-beta-erythroidine, to rat brain tissue. J Neurosci 4: 2906-2911.

Winterer G, Musso F, Konrad A, Vucurevic G, Stoeter P, Sander $\mathrm{T}$ et al (2007). Association of attentional network function with exon 5 variations of the CHRNA4 gene. Hum mol genet 16: 2165-2174. 